\title{
Preclinical testing of a new clot-retrieving wire device using polyvinyl alcohol hydrogel vascular models
}

\author{
Fumio Asakura • Hasan Yilmaz • German Abdo • \\ Lucka Sekoranja • Diego San Millan • \\ Luca Augsburger • Roman Sztajzel • \\ Daniel A. Ruefenacht • Fabienne Perren • \\ Karl-Olof Lovblad • Katsuya Goto
}

Received: 5 May 2006 / Accepted: 20 October 2006 / Published online: 23 November 2006

(C) Springer-Verlag 2006

\begin{abstract}
Introduction Cerebral embolism is the principal cause of cerebral infarction. Recently, mechanical embolectomy has been proposed as an effective method. We performed a preclinical evaluation of a new mechanical clot-retrieving wire.

Methods This clot-retrieving wire consisted of three nitinol loops at the tip of a microguidewire. These three loops could be collapsed into a 0.018-inch wire compatible microcatheter. Each loop was $8 \mathrm{~mm}$ long and $3.5 \mathrm{~mm}$ wide. For simulation, polyvinyl alcohol (PVA) vascular anatomical models of the human carotid (eight models) and vertebrobasilar (three models) circulation were constructed. A pulsatile flow circulation system was used. Embolic clots were produced using pig blood plasma. The microcatheter and the microguidewire were advanced beyond the clot. The wire was then exchanged for the retrieving wire. The microcatheter was then pulled slightly back to open the loops. The clot was then caught by withdrawal of the system. Once caught, the clot was retrieved to the guiding catheter tip. We investigated the following points: ease of device
\end{abstract}

F. Asakura • H. Yilmaz • G. Abdo • D. San Millan •

L. Augsburger $\cdot$ D. A. Ruefenacht $\cdot$ K.-O. Lovblad $(\bowtie)$

Neuroradiology Unit, University Hospital of Geneva,

1211 Geneva, Switzerland

e-mail: karl-olof.Lovblad@hcuge.ch

L. Sekoranja $\cdot$ R. Sztajzel $\cdot$ F. Perren

Neurology Department, University Hospital of Geneva,

Geneva, Switzerland

K. Goto

Neuroendovascular Section, Brain Attack Center,

Ohta Memorial Hospital,

Ohta, Japan deployment, clot capture ability, clot removal against blood flow and removal of the clot out of the introducer system.

Results A total of 104 procedures were performed in 11 PVA models and evaluated. The drop rate was $19 \%$. We succeeded in partial and total recanalization in $51.0 \%$ of the procedures (53/104) within 30 minutes.

Conclusion This new clot-retrieving wire could be useful for mechanical clot extraction in stroke.

Keywords Mechanical thrombectomy . Clot .

Cerebral artery $\cdot$ Vascular model $\cdot$ Recanalization

\section{Introduction}

Embolism from a proximal source is the leading cause of cerebral infarction. Embolism must be considered if a patient with arrhythmia presents with acute neurological signs. Stroke is associated with a short window of opportunity for treatment. In order to dissolve the clot, various approaches have been tried, such as the intravenous administration of streptokinase [1-5] or urokinase [6, 7], intraarterial administration of urokinase $[8,9]$ or prourokinase $[10,11]$, intravenous administration of tissue plasminogen activator (t-PA) [12-17] and intraarterial administration of t-PA [18-20]. Recanalization rates and final outcomes in the patients have been slightly improved, but with an increase in the incidence of hemorrhage. Moreover, some patients cannot be treated by any thrombolytic agent because of contraindications to therapy. New methods are required to treat these patients.

Recently, mechanical embolectomy has been shown to be a rapidly effective method for reducing cerebral 
hemorrhage induced by the thrombolytic agent. It also allows patients to be treated outside the therapeutic window and might globally improve treatment of embolism, when compared to thrombolysis alone. At present, clot-removal devices are under development. Some devices are based on a vacuum system [21-23]; others use ultrasonic vibration [24-27]. However, devices with complex systems are often too stiff to insert into the cerebral vasculature. Indeed, flexibility and simplicity of use are very important for clot removal from cerebral arteries. A few devices are now commercially available [28-30]. The recanalization rate of target vessels was found to be of $53.5 \%$ in a recent study concerning the MERCI device, which might be insufficient for a medical device. Therefore, a new device which has a high efficacy is needed.

A simple and small neuroendovascular clot retrieving device for use in the cerebral vasculature has been developed by the Terumo Corporation (Tokyo, Japan). Before it can be introduced clinically, this device has to be investigated regarding its ease of use, efficacy and safety. We chose to investigate its use in polyvinyl alcohol (PVA) hydrogel vascular models. Indeed, there are no animal models which have a suitable vessel size and geometric characteristics for this study. We also investigated how a clot can be caught by the new device, and how this procedure may fail.

\section{Materials and methods}

Polyvinyl alcohol hydrogel vascular models

PVA models pf the cerebral vasculature [31] were used for the test. In some previous studies of devices, glass or silicon models have been used. Glass models [32, 33] are too rigid and silicon models [34-36] have high wall friction. The friction of the device against the silicon wall is much higher than against the wall of a PVA model, as well as higher than against the human vessel wall [31]. Therefore, we preferred PVA models to silicon or glass models.

We utilized a total of 11 PVA models from Elastrat (Geneva, Switzerland) to test the effects of vessel tortuosity, the effects of the presence of side branches, and the effects of blood flow in dominant vessels and of collateral flow in accordance with our experience (Fig. 1).

For the vertebrobasilar system, we used three models:

No. 1 Symmetrical smooth model

No. 2 Asymmetrical tortuous model, type A (contralateral dominant vessel)

No. 3 Asymmetrical tortuous model, type B (ipsilateral dominant vessel)
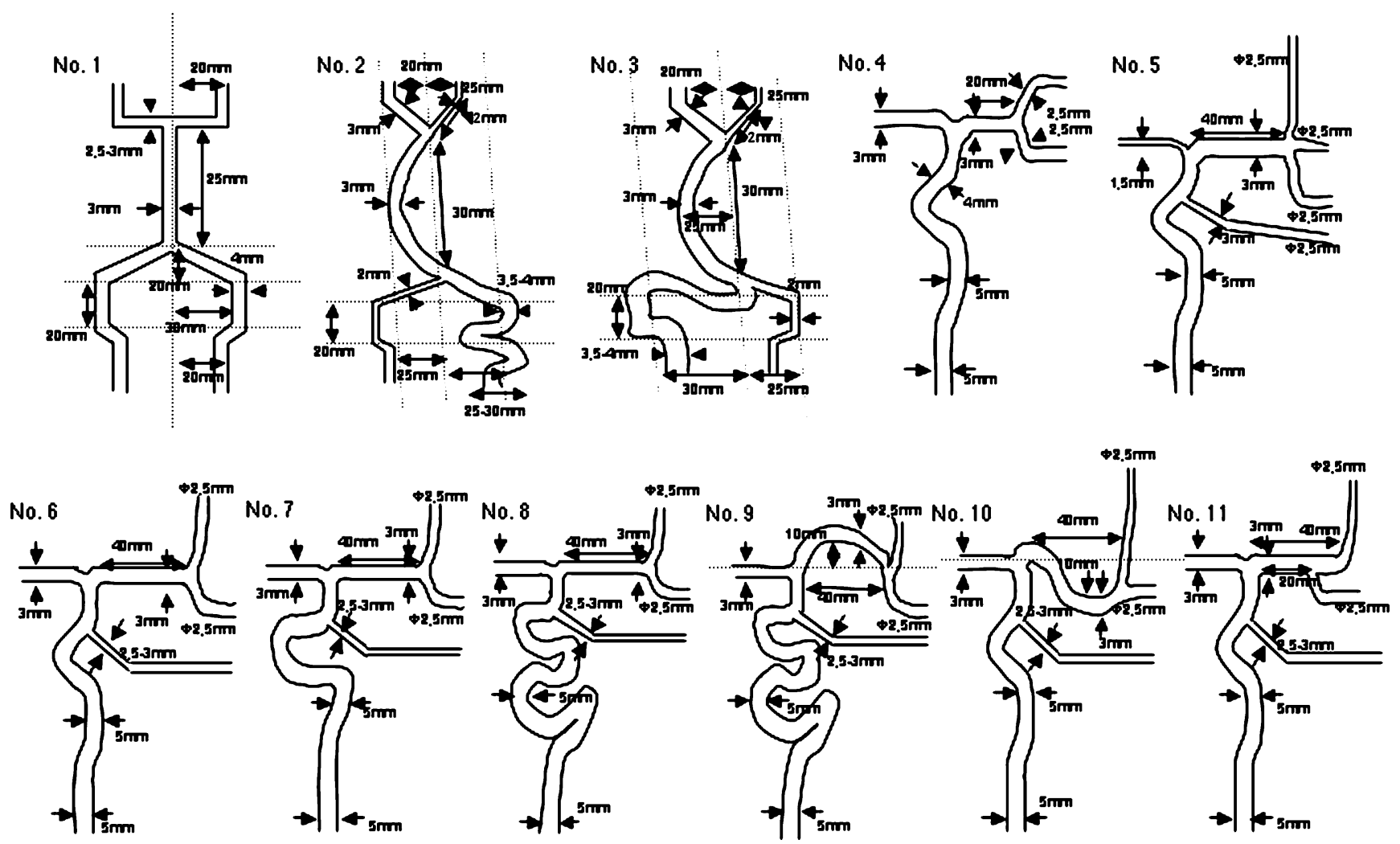

Fig. 1 Cerebral vascular PVA models (three vertebrobasilar artery and eight anterior circulation) 
For simulations involving the middle cerebral artery (MCA), we used eight models ( $A C A$ anterior cerebral artery, Pcom posterior communicating artery):

No. 4 Short MCA model with bifurcation and an anterior communicating artery, with an ACA, without a Pcom

No. 5 Long MCA model with trifurcation and a Pcom, and a small ACA

No. 6 Long MCA model with bifurcation and a Pcom, and a large ACA

No. 7 Long MCA model with bifurcation and a Pcom, and a large ACA (tortuous type)

No. 8 Long MCA model with bifurcation and a Pcom, and a large ACA (very tortuous type)

No. 9 Long tortuous MCA model with bifurcation and a Pcom, with a large ACA (very tortuous type)

No. 10 Long tortuous MCA model with bifurcation and a Pcom, with a large ACA

No. 11 Long MCA model with early bifurcation and a Pcom, with a large ACA

Tested devices

The tested clot-retrieving wire consisted of three nitinol loops at the tip of a 0.014-inch microguidewire (Fig. 2). These three loops were mounted like a tulip at the tip of the microguidewire and they could be collapsed to fit into a 0.018 -inch wire compatible microcatheter. The loop was $8 \mathrm{~mm}$ long and $3.5 \mathrm{~mm}$ wide. Once the three loops had been released from the microcatheter, the two side loops opened like a flower due to their memorized shape. The center loop was rendered radioopaque by the presence of a titanium filament. Clot extraction with this device was comparable to that using a lasso.

Pulsatile flow was produced by a pump (Iwaki magnetic pump, Iwaki, Tokyo, Japan) which simulates physiological blood pressure and collateral flow. The following parameters were used: frequency $60 \mathrm{~Hz}$, wave form pattern CB2, amplitude $1.0 \mathrm{~V}$.

The following microguidewires were used: GT wires 0.012 and 0.016 inch (Terumo), Transend 0.014 inch (Boston Scientific Target, Fremont, Calif.), and SilverSpeed 0.010 inch (MicroTherapeutics, Irvine, Calif.). The following microcatheters were used: Progreat $2.4 \mathrm{~F}$ and $2.7 \mathrm{~F}$ (Terumo), FasTracker 18 (Boston Scientific Cork, Cork, Republic of Ireland) and Rapid Transit (Cordis, Miami, Fl.). The following guiding catheters used were: $6 \mathrm{~F}$ Envoy MPD, 8F Vista Brite tip MDA1 and 9F Vista Brite tip MDA1 (Cordis), and 9F PATLIVE (Clinical Supply, Gifu, Japan). The Introducing sheaths used were $6 \mathrm{~F}$ and $8 \mathrm{~F}$ Brite tip sheath introducers (Cordis, Roden, The Netherlands). The results for each combination of devices were not recorded separately because the operating procedures were modified according to the previous test results.

The tests were performed on a biplane digital subtraction angiography unit (Integris V 3000; Philips Medical Systems, Best, The Netherlands). The contrast agent used was either Iopamiro 300 (Bracco, Milan, Italia) or Omnipaque 350 (Schering Schweiz, Zurich, Switzerland). For training, a few procedures were performed in each model by direct viewing without fluoroscopy.

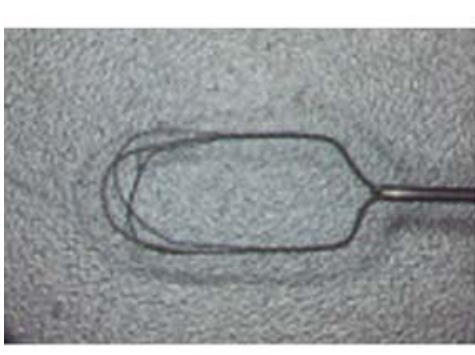

Width of Tip form : $3.5 \mathrm{~mm}$
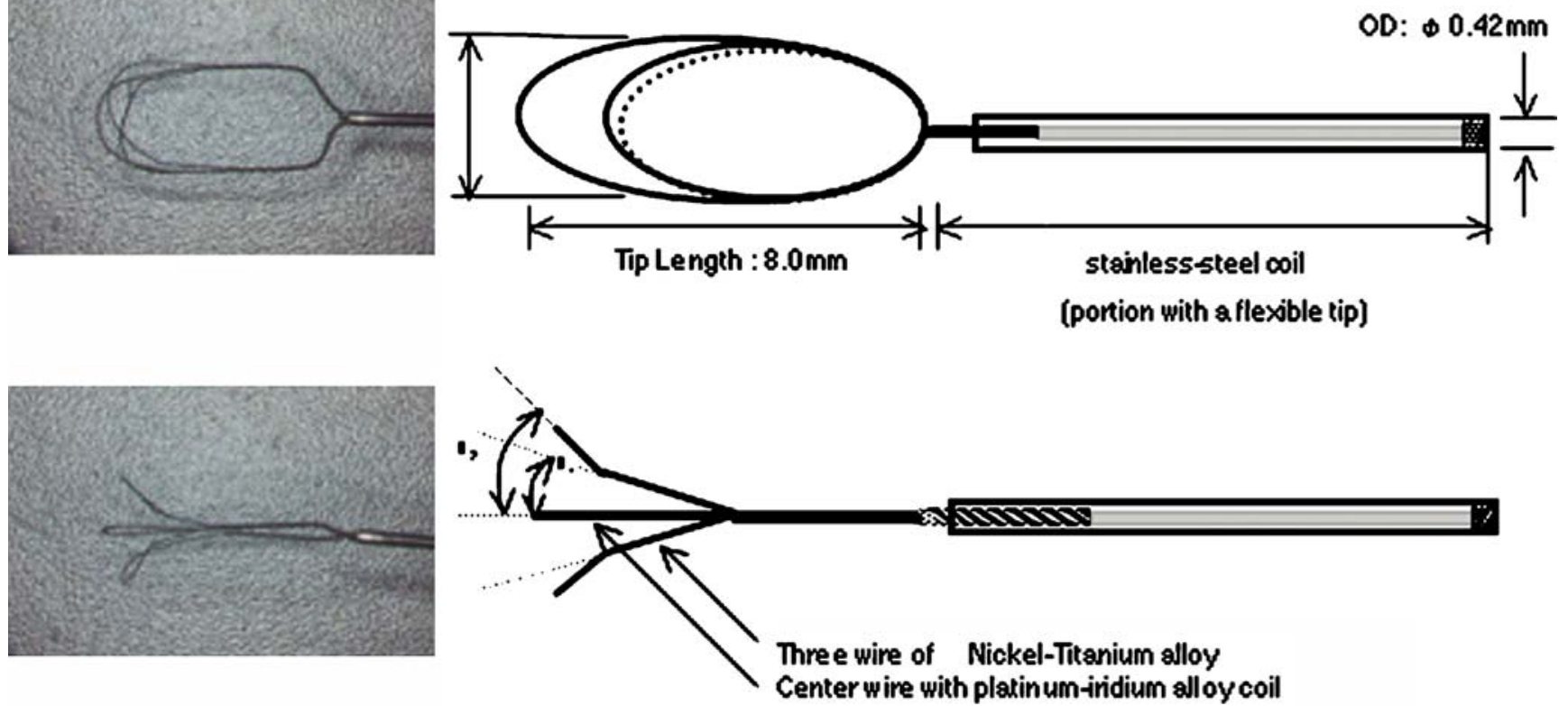

Fig. 2 Clot-retrieving wire (Terumo, Tokyo, Japan) 
Clots

The clots were produced from swine blood. First blood was collected without heparin. Then $45 \mathrm{ml}$ blood was added to $5 \mathrm{ml}$ citric acid 3.8\% (total $50 \mathrm{ml}$ ) (removal of calcium by citric acid), and the mixture centrifuged (3000 rpm, $10 \mathrm{~min}$, room temperature). The plasma was then extracted and $5 \mathrm{ml}$ was mixed $45 \mathrm{ml}$ lactic acid Ringer's solution $45 \mathrm{ml}$ ), and the mixture stirred (chelating with calcium). Finally the fibrin lump is picked and trimmed. Clots of any size could be produced from the fibrin lump, and depending on the amount of calcium used, clots could be softer or harder.

Test methods

For simulation of commonly encountered clinical conditions, the in vitro vascular models described above were constructed. Low-friction, transparent PVA vascular models were used and integrated into a pulsatile flow system providing physiological conditions. Embolic debris was simulated by introducing fibrin clots obtained from pig blood plasma hardened with lactic acid. The clot location was recorded and clot retrieval with the wire was attempted through both braided and nonbraided microcatheters. The microguidewire-microcatheter system was advanced such that the tip position reached distal to the clot. The regular wire was then exchanged for the retrieving wire system to reach the tip of the microcatheter. The microcatheter was then pulled slightly back to allow opening of the loops. The clot was caught by progressively withdrawing the system. Once caught, the clot was retrieved into the guiding catheter tip (Fig. 3).

We investigated the following points: (1) ease of device deployment; (2) clot capture ability; (3) clot removal against blood flow; and (4) removal of the clot out of the introducer system. A total of 104 procedures in 11 PVA models were performed and evaluated. All procedures were performed by well-trained neuroendovascular surgeons (Dr. Hasan Yilmaz, Dr. German Abdo and Dr. Fumio Asakura, Neuroradiology Section, Geneva University Hospital). They chose a combination of devices (clot-retrieving wires, microcatheters, guiding catheters, introducing sheaths) and modified the operation procedures based on their personal experience.

First, we performed procedures in simple PVA models with small and soft clots. Then, gradually, we performed procedures in more complicated models with larger and harder clots. Intentionally, we also tried to perform procedures in more difficult situations which we devised. We did this in order to determine which elements affected the difficulty of clot retrieval. In order to determine our learning curve, we measured the time for the procedure from insertion of the microcatheter to retrieval of a clot through the introducer in the last five procedures.
We observed the following effects:

1. Effects of vessel geometry on the device: Cerebral vessels are very tortuous which renders insertion of devices difficult. In order to reach a clot located in a cerebral artery, the device must be inserted and guided through the tortuous vessels. When the clot is removed, it has to pass through the angles, bifurcations and the orifices of branches. We evaluated the influence of vessel geometry on the device.

2. Blood flow effects: The clot is pushed forward by the strong blood flow. Thus, clot retrieval has to be done against the blood flow. We evaluated the influence of blood flow on clot retrieval.

3. Clot quality: The quality of a clot depends on many factors (platelets, fibrin, etc.). The hardness of clots is influenced by the different constituents. We took clot consistency into consideration before retrieval.

4. Compatibility of the device with other devices: In order to effectively use the device, an introducing sheath, a guiding catheter and a microcatheter are needed. We evaluated the compatibility between the device and these other components.

\section{Results}

We were able to achieve recanalization in 53 out of 104 procedures. Thus the total or partial recanalization rate (TIMI grade 2-3) was $51.0 \%$. However, the clot retrieval rate was $31.7 \%$, because we lost clots during retrieval in 20 procedures $(19.2 \%)$. In these cases, clots were washed away to other vessels or dropped in the introducing sheath. The failure rate was $49.0 \%$ (51 of 104 procedures; Table 1).

The time for recanalization of the target vessels varied between $9 \min 34 \mathrm{~s}$ and $21 \min 23 \mathrm{~s}$ (average $14 \mathrm{~min} 51 \mathrm{~s}$ ) for the last five procedures (Table 2). In the final procedure, we could not recanalize the target vessel within $30 \mathrm{~min}$ and we stopped the procedure.

We present in the following sections a comparative evaluation of the various devices used as components of the system.

Microguidewire Initial passage through the clot-occluded vessel segments was easiest to perform with the Terumo GT wire 16, whereas the Transend 14 and SilverSpeed 10 wires could hardly pass the side of the clot when the target vessel was completely occluded by the clot.

Microcatheter It was very difficult to use the clot-retrieval wire through nonbraided microcatheters (FasTracker 18) in tortuous vessels because of strong friction, likely due to catheter lumen deformation in tightly curved vessel seg- 

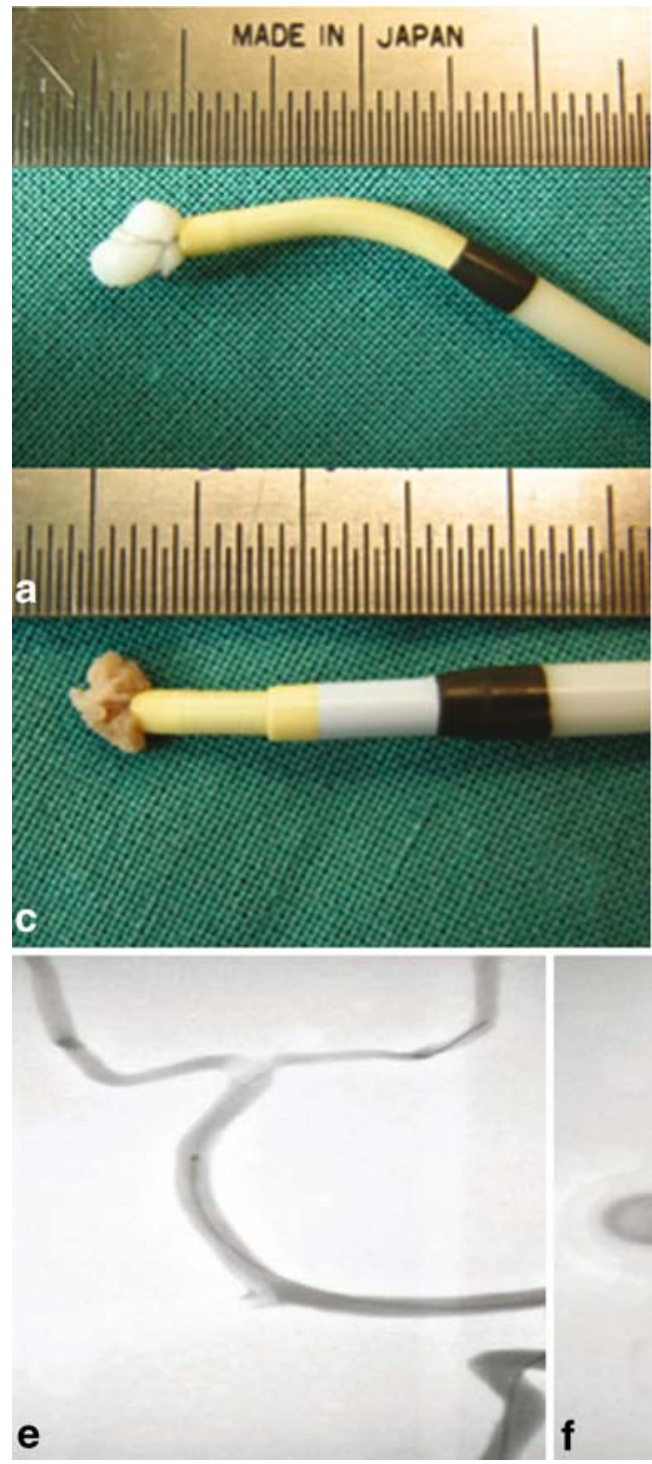
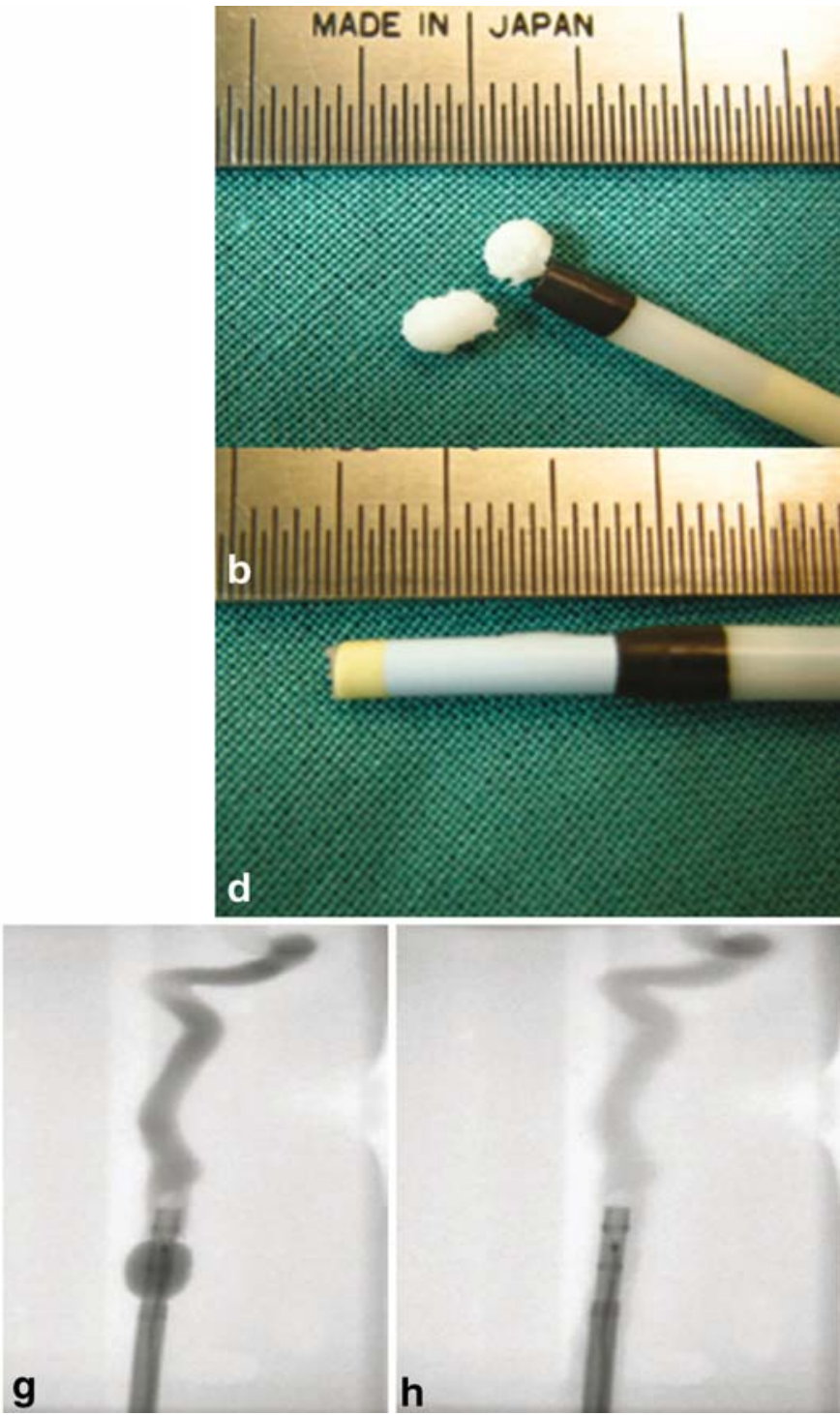

Fig. 3 a, b A hard clot is broken at the tip of a $6 \mathrm{~F}$ guiding catheter or $6 \mathrm{~F}$ introducer. $\mathbf{c}, \mathbf{d} \mathrm{A}$ soft clot is able to go into an $8 \mathrm{~F}$ guiding catheter when it is squeezable. $\mathbf{e}-\mathbf{h}$ Effect of flow control by a guiding catheter with a balloon

ments. However, braided microcatheters allowed access without difficulty even in tortuous vessels. Moreover, navigability was excellent with the Progreat catheter.

Guiding catheter Clots were more stable at the tip of the $8 \mathrm{~F}$ catheter than at the tip of the $6 \mathrm{~F}$ catheter. Hard clots could hardly be taken into the $8 \mathrm{~F}$ catheter (Fig. $3 \mathrm{a}$ and $\mathrm{b}$ ). When we lost a clot from the clot-retrieval wire around the guiding catheter tip with balloon during flow control, we were able to catch the clot by aspiration through the guiding catheter (Fig. $3 c$ and d).

Introducing sheath Sometimes we lost a clot from the tip of a $6 \mathrm{~F}$ introducer because the clot would often not be completely loaded into the $6 \mathrm{~F}$ guiding catheter; this would occur with the $8 \mathrm{~F}$ introducer at the level of the valve, where we could not squeeze and load the clot completely into the guiding catheter.
Clot-retrieving wire Clot-retrieving wires never broke. It was very difficult to catch the clots at T-shaped junctions and around sharp corners. We were able to retrieve clots which were larger than the loops of the clot-retrieving wire. Sometimes, we lost a clot at the orifice of the branches, at sharp curves and in widely spread vessels. The clotretrieving wire had better radioopacity than another comparator clot-retrieving device (Fig. 4).

\section{Discussion}

Intravenous administration of t-PA within 3 hours of the onset of ischemic stroke has shown to result in an improvement in clinical outcome at 3 months, despite an increased incidence of symptomatic intracerebral hemor- 
Table 1 Results of all procedures in all PVA models

\begin{tabular}{lllll}
\hline $\begin{array}{l}\text { Model } \\
\text { number }\end{array}$ & Procedures & $\begin{array}{l}\text { Total or partial } \\
\text { recanalization }\end{array}$ & Failure $^{\mathrm{a}}$ & Dropped $^{\mathrm{b}}$ \\
\hline 4 & 4 & 1 & 3 & 1 \\
1 & 4 & 1 & 3 & 1 \\
6 & 8 & 7 & 1 & 3 \\
3 & 4 & 3 & 1 & 0 \\
7 & 10 & 6 & 4 & 1 \\
2 & 7 & 5 & 2 & 2 \\
2 & 8 & 5 & 3 & 5 \\
10 & 9 & 7 & 2 & 3 \\
5 & 4 & 0 & 4 & 0 \\
5 & 7 & 6 & 1 & 1 \\
9 & 6 & 4 & 2 & 1 \\
8 & 10 & 2 & 8 & 0 \\
11 & 23 & 6 & 17 & 2 \\
Total & 104 & 53 & 51 & 20 \\
\hline
\end{tabular}

${ }^{\mathrm{a}}$ We could not catch the clot with the clot-retrieving wire.

${ }^{\mathrm{b}}$ We dropped the clot after catching it during the procedure.

rhage [12]. To reduce the incidence of hemorrhage, direct administration of the thrombolytic agent via a microcatheter has been tried. In the PROACT I trial, the recanalization rate of patients treated with pro-urokinase was $57.7 \%$ compared to $14.3 \%$ for the control group. However, hemorrhage with clinical deterioration within 24 hours occurred in $15.4 \%$ of the pro-urokinase group compared to $7.1 \%$ for the control group [10]. In the PROACT II trial, the recanalization rate was $66 \%$ with pro-urokinase associated with heparin, compared to $18 \%$ for the group which received heparin alone. However, hemorrhage with clinical deterioration within 24 hours occurred in $10 \%$ of the prourokinase and heparin group, compared to $2 \%$ for the control group [11]. The efficacy of intraarterial administration of t-PA remains controversial. Moreover, there are patients who are seen within the 3-hour therapeutic window with contraindications to receiving any thrombolytic agent.

Mechanical embolectomy has been proposed as a rapid and effective means for recanalization. Usually, mechanical embolectomy can be performed with a small amount of heparin during the procedure. This may reduce the incidence of hemorrhagic events. Therefore, patients, who are in the hyperacute stage of cerebral stroke but who have some kind of contraindication to thrombolytic therapy can be treated by mechanical embolectomy.

There are a few commercially available mechanical clotretrieving devices for cerebral stroke, including the Merci retriever (Concentric Medical, Mountain View, Calif.) and the Catch system (Balt, Montmorency, France) [28-30]. Unfortunately, we could not acquire these devices for these test for comparison. Also, from a technological point of
Table 2 Time for the procedures in PVA model no. 11

\begin{tabular}{|c|c|c|c|c|}
\hline Trial & Procedure & $\begin{array}{l}\text { Time to } \\
\text { catch the } \\
\text { clot }(\mathrm{min} / \mathrm{s})\end{array}$ & $\begin{array}{l}\text { Time to } \\
\text { remove the } \\
\text { clot through } \\
\text { the introducer } \\
(\mathrm{min} / \mathrm{s})\end{array}$ & Result \\
\hline 1 & 1 & $6 / 50$ & $9 / 34$ & Total removal \\
\hline \multirow[t]{5}{*}{2} & 1 & - & - & Failure \\
\hline & 2 & - & - & Failure \\
\hline & 3 & - & - & Failure \\
\hline & 4 & - & - & Failure \\
\hline & 5 & $10 / 20$ & $11 / 56$ & Total removal \\
\hline \multirow[t]{7}{*}{3} & 1 & - & - & Failure \\
\hline & 2 & - & - & Failure \\
\hline & 3 & - & - & Failure \\
\hline & 4 & $10 / 45$ & $12 / 27$ & $\begin{array}{l}\text { Half the clot } \\
\text { removed }\end{array}$ \\
\hline & 5 & - & - & Failure \\
\hline & 6 & - & - & Failure \\
\hline & 7 & $20 / 1$ & $21 / 23$ & Total removal \\
\hline \multirow[t]{6}{*}{4} & 1 & - & - & Failure \\
\hline & 2 & $9 / 55$ & - & Dropped \\
\hline & 3 & - & - & Failure \\
\hline & 4 & - & - & Failure \\
\hline & 5 & - & - & Failure \\
\hline & 6 & $14 / 51$ & $16 / 30$ & Total removal \\
\hline \multirow[t]{4}{*}{5} & 1 & - & - & Failure \\
\hline & 2 & - & - & Failure \\
\hline & 3 & - & - & Failure \\
\hline & 4 & - & - & $\begin{array}{l}\text { Procedure stopped } \\
\text { (>30 min) }\end{array}$ \\
\hline
\end{tabular}

view, it might be interesting to develop a device with a thinner wire. Furthermore, as with the Merci device, we believe that this new system should be used together with a distal balloon-mounted guiding catheter in clinical practice and we would recommend it strongly. However, in this in vitro study, stopping the pump corresponds to the temporal occlusion obtained with a distal balloon-mounted guiding catheter, thus reducing the risk of clot loss during the retrieval step.

The total and partial recanalization rate (TIMI grade 2$3)$ using the clot retrieval device was $51.0 \%(53 / 104$ procedures), which at first glance seems to be low. However, the recanalization rate was $53.5 \%$ in the MERCI trial [30], which was an in vivo trial. We performed all procedures in vitro using models. We used fibrin clots from pig blood and saline for circulation in the PVA models. To occlude the vessels in the PVA models we had to use clots which had a diameter 1.2-1.5 times larger than the vessels. In PVA models with saline, there is no adhesive material, which is why we needed to use large clots. In fact, small microguidewires which had spring tips could not pass the side of the clots. In our models, flow pressure caused the 
Fig. 4 Radiographs of clot retrievers in PVA model no. 11 (left new Terumo clot-retrieving wire, right Catch clot-retrieving wire (Balt, Montmorency, France)

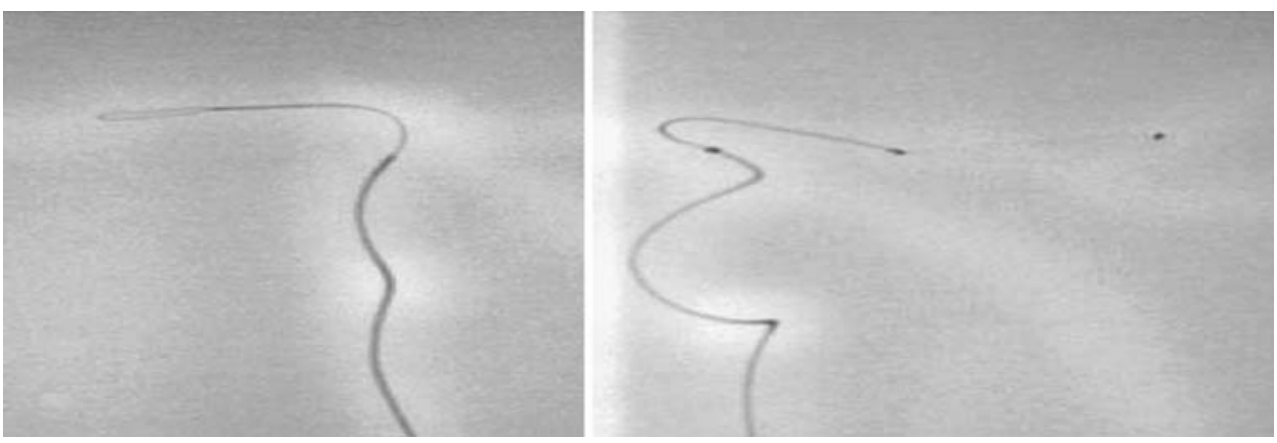

clots to occlude the vessel tightly because the PVA surface was very smooth. Usually, in the clinical setting we can maneuver a microguidewire with spring tips past the side of a clot during thrombolysis. Therefore, the situation we encountered in the PVA model seemed to be more difficult than in humans.

We tried to simulate many difficult situations that might arise in clinical practice to establish the limitations of the clot-retrieving wire. We performed procedures several times under the same conditions when we failed, in order to determine the reason for the failure. To confirm the effect of clot hardness, we used some hard clots made from swine fibrin and calcium. They were hard as a stone. It was quite difficult to catch such a clot, because the loops slipped on the surface of the clot.

To determine the best guiding catheter size for the device, various sizes were used for the test. First, we used a $6 \mathrm{~F}$ guiding catheter, because the 0.018 -inch wire compatible microcatheter needed a 5-6F guiding catheter. But clots were hardly removed through a $6 \mathrm{~F}$ catheter. The diameter of target vessels is around $3.0-4.0 \mathrm{~mm}$, which is larger than the inner diameter of a $6 \mathrm{~F}$ guiding catheter and introducer. It seems a little bit larger than the inner diameter of an $8 \mathrm{~F}$ guiding catheter and introducer. Most clots can be squeezed to a degree to enter the lumen of an $8 \mathrm{~F}$ introducer sheath that has an internal diameter of $2 \mathrm{~mm}$. When clots could be squeezed into the lumen, we could put them into the $8 \mathrm{~F}$ guiding catheter. Therefore, we recommend using at least an $8 \mathrm{~F}$ guiding catheter and introducer with this device.

To stabilize the clots at the tip of the guiding catheters, strong manual aspiration through the guiding catheters was performed. To catch a clot, the retrieving device should be pulled while keeping the position of the microcatheter stable in order to make the loops smaller. Very fragile clots were fragmented by the loops. Besides these problems related to the clots themselves, we did not encounter any problems that we consider to have been related to the system design.

When clots fragmented at the tip of the guiding catheter, aspiration through the guiding catheters and introducers was also performed to remove the fragments. In order to develop a standard procedure with this device, some procedures were considered wasted for training. These failures were included. Therefore, we can expect higher recanalization rates in humans.

The main limitations of this study are the absence of comparison with other devices and no numerical evaluation of success. Regarding the absence of comparative data with other devices, we performed this test to observe and evaluate how the new device worked in vitro. We also had to define the interventional procedure, because our test was the first for this device. On the other hand, the interventional procedures for the Merci retriever and Catch system are well known. Therefore, we did not compare the new device with others. Regarding the absence of numerical evaluation, except for success rate and procedure time, the main purpose of this test was to observe how the new device worked in various situations, and to define an operating procedure with suitable devices. Combinations of devices and operating procedures were modified many times. Therefore, we do not have sufficient quantitative data for the same situation.

\section{Conclusion}

This new clot-retrieving wire was developed with the technology based on the 0.018-inch microguidewire for intracranial vessels. Various characteristics were observed with preclinical testing in human-like in vitro PVA models. The recanalization rate within a 30-minute time limit using the Terumo clot-retrieving wire was over 50\%. The performance of the device in this preclinical test was encouraging and justifies progressing to a feasibility test in a clinical setting without hesitation. Also the use of PVA models allows animal testing to be avoided or at least to be used only at a later stage to test the devices.

Conflict of interest statement We declare that we have no conflict of interest. 


\section{References}

1. Multicentre Acute Stroke Trial-Italy (MAST-I) Group (1995) Randomised controlled trial of streptokinase, aspirin, and combination of both in treatment of acute ischaemic stroke. Lancet 346:1509-1514

2. Hommel M, Boissel JP, Cornu C, Boutitie F, Lees KR, Bessorn G, Leys D, Amarenio P, Bogart M (1995) Termination of trial of streptokinase in severe acute ischaemic stroke. MAST Study Group. Lancet 345:57

3. Donnan GA, Davis SM, Chambers BR, Gates PC, Hankey GJ, McNeil JJ, Rosen D, Stewart-Wynne EC, Tuc RR (1995) Trials of streptokinase in severe acute ischaemic stroke. Lancet 345:578579

4. Multicenter Acute Stroke Trial-Europe Study Group (1996) Thrombolytic therapy with streptokinase in acute ischemic stroke. N Engl J Med 335:145-150

5. Cornu C, Boutitie F, Candelise L, Boissel JP, Donnan GA, Hommel M, Jaillard A, Lees KR (2000) Streptokinase in acute ischemic stroke: an individual patient data meta-analysis: The Thrombolysis in Acute Stroke Pooling Project. Stroke 31:15551600

6. Fletcher AP, Alkjaersig N, Lewis M, Tulevski V, Davies A, Brooks JE, Hardin WB, Landau WM, Raichle ME (1876) A pilot study of urokinase therapy in cerebral infarction. Stroke 7:135-142

7. Hanaway J, Torack R, Fletcher AP, Landau WM (1976) Intracranial bleeding associated with urokinase therapy for acute ischemic hemispheral stroke. Stroke 7:143-146

8. Jahan R, Duckwiler GR, Kidwell CS, Sayre JW, Gobin YP, Villablanca JP, Saver J, Starkman S, Martin N, Vinuela F (1999) Intraarterial thrombolysis for treatment of acute stroke: experience in 26 patients with long-term follow-up. AJNR Am J Neuroradiol 20:1291-1299

9. Arnold M, Schroth G, Nedeltchev K, Loher T, Remonda L, Stepper F, Sturzenegger M, Mattle HP (2002) Intra-arterial thrombolysis in 100 patients with acute stroke due to middle cerebral artery occlusion. Stroke 33:1828-1833

10. del Zoppo GJ, Higashida RT, Furlan AJ, Pessin MS, Powley HA, Gent M (1998) PROACT: a phase II randomized trial of recombinant pro-urokinase by direct arterial delivery in acute middle cerebral artery stroke. Stroke 29:4-11

11. Furlan A, Higashida R, Wechsler L, Gent M, Rowley H, Kase C, Pessin M, Ahuja A, Callahan F, Clark WM, Silver F, Rivera $\mathrm{F}(1999)$ Intra-arterial prourokinase for acute ischemic stroke. The PROACT II Study: a randomized controlled trial. Prolyse in Acute Cerebral Thromboembolism. JAMA 282:2003-2011

12. The National Institute of Neurological Disorders and Stroke rt-PA Stroke Study Group (1995) Tissue plasminogen activator for acute ischemic stroke. N Engl J Med 333:1581-1587

13. The ATLANTIS, ECASS, and NINDS rt-PA Study Group Investigators (2004) Association of outcome with early stroke treatment: pooled analysis of ATLANTIS, ECASS, and NINDS rt-PA stroke trials. Lancet 363:768-774

14. Molina CA, Alexandrov AV, Demchuk AM, Saqqur M, Uchino K, Alvarez-Sabin J (2004) Improving the predictive accuracy of recanalization on stroke outcome in patients treated with tissue plasminogen activator. Stroke 35:151-157

15. Trouillas P, Derex L, Philippeau F, Nighoghossian N, Honnorat J, Hanss M, Ffrench P, Adeleine P, Dechavanne M (2004) Early fibrinogen degradation coagulopathy is predictive of parenchymal hematomas in cerebral rt-PA thrombolysis. A study of 157 cases. Stroke 35:1323-1328

16. Lee KY, Kin DI, Kim SH, Lee SI, Chung HW, Shim YW, Kim SM, Heo JH (2004) Sequential combination of intravenous recombinant tissue plasminogen activator and intra-arterial urokinase in acute ischemic stroke. AJNR Am J Neuroradiol 25:1470-1475

17. Ribo M, Molina CA, Rovira A, Quintana M, Delgado P, Montaner J, Grive E, Arenillas JF, Alvarez-Sabin J (2005) Safety and efficacy of intravenous tissue plasminogen activator stroke treatment in the 3- to 6-hour window using multimode transcranial Doppler/MRI selection protocol. Stroke 36:602-606

18. Eckert B, Kucinski T, Neumaier-Probst E, Fiehler J, Rother J, Zeumer H (2003) Local intra-arterial fibrinolysis in acute hemispheric stroke: effect of occlusion type and fibrinolytic agent on recanalization success and neurological outcome. Cerebrovasc Dis 15:258-263

19. Bourekas EC, Slivka AP, Shah R, Sunshine J, Suarez JI (2004) Intraarterial thrombolytic therapy within 3 hours of the onset of stroke. Neurosurgery 54:39-44

20. Johnson DM, Kramer DC, Cohen E, Rochon M, Rosner M, Weinberger J (2005) Thrombolytic therapy for acute stroke in late pregnancy with intra-arterial recombinant tissue plasminogen activator. Stroke 36:e53-e55

21. Fava M, Loyola S, Huete I (2000) Massive pulmonary embolism: treatment with the Hydrolyser thrombectomy device. J Vasc Interv Radiol 11:1159-1164

22. Bellon RJ, Putman CM, Budzik RF, Pergolizzi RS, Reinking GF, Norbash AM (2001) Rheolytic thrombectomy of the occluded internal carotid artery in the setting of acute ischemic stroke. AJNR Am J Neuroradiol 22:526-530

23. Nishida T, Nakamura M, Tsunoda T, Iijima R, Shiba M, Wada M, Nakajima R, Kitagawa Y, Yajima S, Wakayama M, Shibuya K, Yamaguchi T (2002) A case of acute myocardial infarction treated with a new thrombectomy system. Catheter Cardiovasc Interv 55:239-243

24. Siegel RJ, Gunn J, Ahsan A, Fishbein MC, Bowes RJ, Oakley D, Wales C, Steffen W, Campbell S, Nita H, Wills T, Silverton P, Myler RH, Cumberland DC (1994) Use of therapeutic ultrasound in percutaneous coronary angioplasty: experimental in vitro studies and initial clinical experience. Circulation 89:1587-1592

25. Rosenschein U, Roth A, Rassin T, Basan S, Laniado S, Miller HI (1997) Analysis of coronary ultrasound thrombolysis endpoints in acute myocardial infarction (ACUTE trial): results of the feasibility phase. Circulation 95:1411-1441

26. Berlis A, Lutsep H, Barnwell S, Norbash A, Wechsler L, Jungreis CA, Woolfenden A, Redekop G, Hartmann M, Schumacher M. (2004) Mechanical thrombolysis in acute ischemic stroke with endovascular photoacoustic recanalization. Stroke 35:1112-1116

27. Smikahl J, Yeung D, Wang S, Semba CP (2005) Alteplase stability and bioactivity after low-power ultrasonic energy delivery with the OmniSonics resolution system. J Vasc Interv Radiol 16:385-389

28. Mayer TE, Hamann GF, Brueckmann HJ (2002) Treatment of basilar artery embolism with a mechanical extraction device: necessity of flow reversal. Stroke 33:2232-2235

29. Martinez H, Zoarski GH, Obuchowski AM, Stallmayer MJ, Papangelou A, Airan-Javia S (2004) Mechanical thrombectomy of the internal carotid artery and middle cerebral arteries for acute stroke by using the retriever device. AJNR Am J Neuroradiol 25:1812-1815

30. Becker KJ, Brott TG (2005) Approval of the MERCI clot retriever. A critical view. Stroke 36:400-403

31. Ohta M, Handa A, Iwata H, Rufenacht DA, Tsutsumi S (2004) Poly-vinyl alcohol hydrogel vascular models for in vitro aneurysm simulations: the key to low friction surfaces. Technol Health Care $12: 225-233$ 
32. Roach MR, Scott S, Ferguson GG (1972) The hemodynamic importance of the geometry of bifurcations in the circle of Willis (glass model studies). Stroke 3:255-267

33. Steiger HJ, Liepsch DW, Poll A, Reulen HJ (1988) Hemodynamic stress in terminal saccular aneurysms: a laser-Doppler study. Heart Vessels 4:162-169

34. Kerber CW, Heilman C (1992) Flow dynamics in the human carotid artery: I. Preliminary observations using a transparent elastic model. AJNR Am J Neuroradiol 13:173-180
35. Gailloud P, Muster M, Piotin M, Mottu F, Murphy KJ, Fasel JHD, Ruefenacht DA (1999) In vitro models of intracranial arteriovenous fistulas for the evaluation of new endovascular treatment materials. AJNR Am J Neuroradiol 20:291295

36. Sugiu K, Martin JB, Jean B, Gailloud P, Mandai S, Ruefenacht DA (2003) Artificial cerebral aneurysm model for medical testing, training, and research. Neuro Med Chir (Tokyo) 43:69-73.3 